
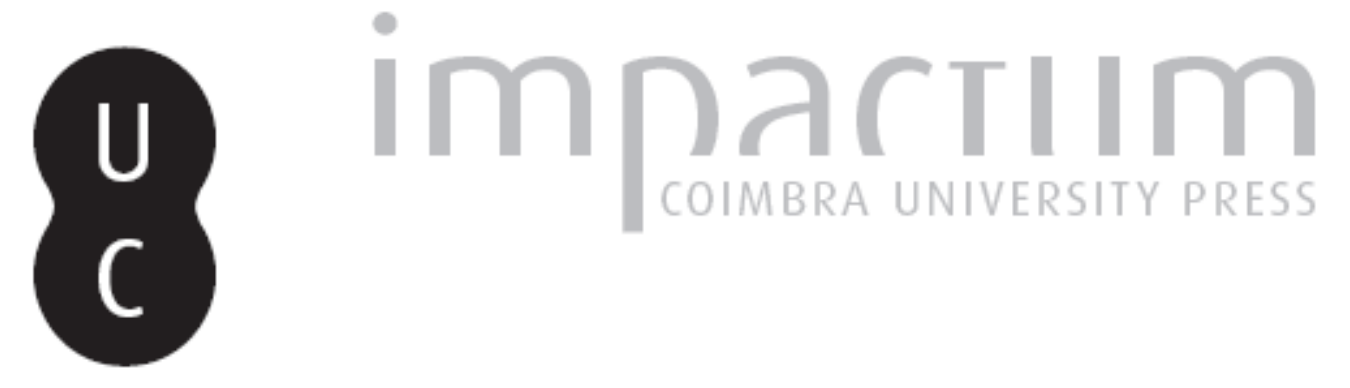

Uma tessela dantesca no poema Soldati de Ungaretti

Autor(es): $\quad$ Spila, Cristiano

Publicado por: Imprensa da Universidade de Coimbra

URL persistente:

URI:http://hdl.handle.net/10316.2/42646

DOI:

DOI:https://doi.org/10.14195/0870-8584_2_12

Accessed : $\quad$ 26-Apr-2023 03:53:42

A navegação consulta e descarregamento dos títulos inseridos nas Bibliotecas Digitais UC Digitalis, UC Pombalina e UC Impactum, pressupõem a aceitação plena e sem reservas dos Termos e Condições de Uso destas Bibliotecas Digitais, disponíveis em https://digitalis.uc.pt/pt-pt/termos.

Conforme exposto nos referidos Termos e Condições de Uso, o descarregamento de títulos de acesso restrito requer uma licença válida de autorização devendo o utilizador aceder ao(s) documento(s) a partir de um endereço de IP da instituição detentora da supramencionada licença.

Ao utilizador é apenas permitido o descarregamento para uso pessoal, pelo que o emprego do(s) título(s) descarregado(s) para outro fim, designadamente comercial, carece de autorização do respetivo autor ou editor da obra.

Na medida em que todas as obras da UC Digitalis se encontram protegidas pelo Código do Direito de Autor e Direitos Conexos e demais legislação aplicável, toda a cópia, parcial ou total, deste documento, nos casos em que é legalmente admitida, deverá conter ou fazer-se acompanhar por este aviso. 


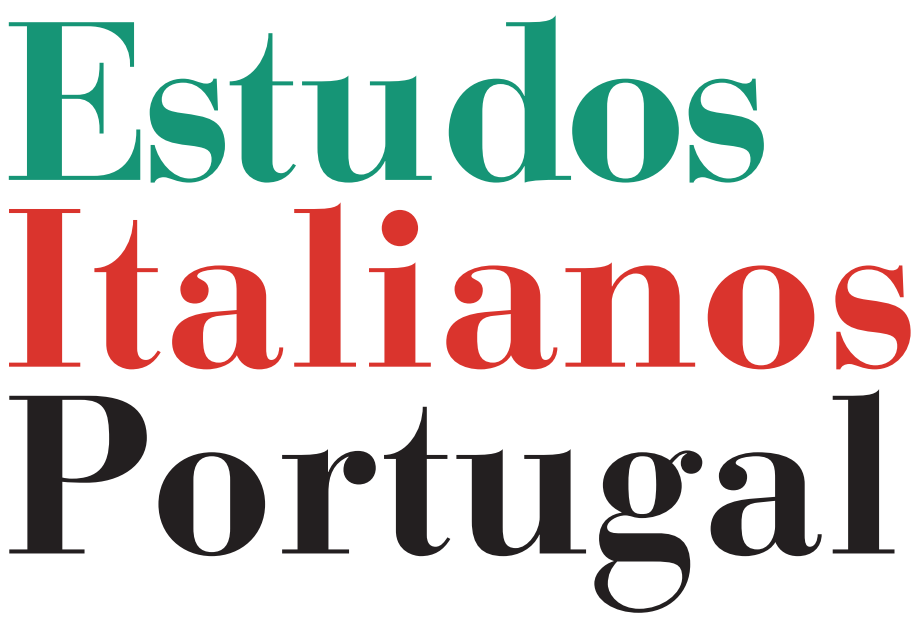

Instituto

Italiano

de Cultura

de Lisboa

Nova Série

$\mathbf{N}^{\mathbf{0}} 2$ 


\title{
UMA TESSELA DANTESCA NO POEMA SOLDATI DE UNGARETTI
}

\author{
Cristiano Spila*
}

É NO POEMA ALLEGRIA DE UngaretTi que se funda toda uma corrente crítica, em particular pelo que diz respeito à elaboração temática e retórica e ao problema das fontes, na ligação entre poéticas históricas e execução individual. Já Ossola punha em destaque a complexidade genética do texto poético de Ungaretti, no trabalho de refuncionalização de estilemas literários, pontualizando a inserção da sua escrita, não no filão do absoluto e do imediato, porquanto desprovida de qualquer ingerência ou interferência de conotações literárias, mas antes no sagaz uso de um filtro compositivo a que não faltam agudos contributos e agudas referências. Se a escrita, como nota Ossola, é "il lento mutarsi per ripetizioni e variazioni, dei luoghi in nuovi segni poetici"1, então também no texto de Ungaretti não faltam grandes tesselas mnemónicas, consequência e, da mesma feita, expressão, das leituras do poeta ${ }^{2}$.

* Cristiano Spila é doutorado em Italianística pela Universidade de Roma, La Sapienza, dedicando-se à literatura contemporânea. Colaborou no Dizionario delle Opere da Letteratura italiana Einaudi coordenada por Asor Rosa e escreveu sobre D’Arrigo (Il mostro barocco, Pescara, 1997), Vigolo, Boine, Manganelli. Mais recentemente, preparou a edição de Giorgio Bassani, Italia da salvare (Torino, 2005).

1 C. Ossola, Giuseppe Ungaretti, Milano, Mursia, 1975-1982, p. 30.

2 Uma investigação acerca do funcionamento e do dinamismo da intertextualidade ungarettiana, feita de reminiscências e de recriações originais, é feita por P. Montefoschi, Ungaretti. Le eclissi della memoria, Napoli, ESI, 1988. 
Entre essas leituras e sugestões, um lugar verdadeiramente significativo ocupa-o Dante: especificamente, o Dante do Inferno, de tal forma que o seu exemplo não se limita a uma fruição inconsciente, mas se traduz em adaptações intencionais da escrita poética, aliás em fulminantes notações metafórico-expressivas, nas quais é possível identificar uma marca de Ungaretti. De resto, recorrer à categoria de intertextualidade para definir as suas relações com um texto como o de Dante põe em evidência também os mecanismos de reutilização, no sentido da memória que, nos seus aspectos gerais, governa as escolhas expressivas do poeta e, na sua especificidade, as escolhas que dizem respeito ao léxico e à métrica, de particular significado com referência ao reuso formal da tradição por parte do poeta moderno. Atentemos, pois, no caso de Soldati. A escolha de uma tessela dantesca põe a descoberto as motivações profundas do nó indissolúvel que une psicologia e estilo: na sua base, encontram-se as sugestões de uma sensibilidade eivada por uma condição existencial extrema, bem como a consciência de uma relação diferente com a realidade, a imporem ao poeta um empenho consciente de renovação dos próprios meios expressivos. Uma renovação que se torna tanto mais eficaz quanto mais intensas são as referências a bases que vêm de longe e a módulos da memória que, conforme veremos, são potenciados nas suas virtualidades ocultas.

A composição de Ungaretti, que já foi definida como "uno dei più straordinari hiperbaton della poesia del Novecento italiano", assenta sobre uma única comparação que exprime o sentido de precariedade da vida do soldado: de iminente ameaça de morte, símbolo, a um nível mais geral, de quanto de provisório há na existência humana. A recon-

3 D. Puccini, "Ungaretti traduttore di Góngora", in Atti del Convegno Internazionale su Giuseppe Ungaretti (Urbino, 3-6 ottobre 1979), a cura di C. Bo, M. Petrucciani, M. Bruscia, M. C. Angelini, E. Cardone, D. Rossi, Urbino, Quattroventi, 1981, t. 1, p. 522. 
dução simbólica do mundo humano ao vegetal é valorizada pelo termo de comparação, que é o drama da vida dos soldados na guerra. Se, no caso das folhas, a separação e a queda do ramo são certas, para os soldados a morte configura-se como antecipação imaginada, como espera incerta e ameaçadora: o sentido de precariedade é dado pela ligação metafórica do Outono com a guerra, que é termo implícito.

Da constância estrutural deste "antichissimo paragone biblico-mimnermiano"4, com os seus automatismos metafóricos, deriva, pois, o núcleo figurativo de Soldati, como o conhecemos na sua redacção definitiva:

\author{
Soldati \\ Bosco di Courton luglio 1918 \\ Si sta \\ come d'autunno \\ sugli alberi \\ le foglie
}

Se considerarmos a estrutura do núcleo metafórico do poema (o fio condutor da precariedade humana), verificamos que se sugere uma congruência relevante e significativa com a comparação de Dante, na Commedia, em Inferno, III, 112-114. Poder-nos-ia servir de guia no processo de redução da complexidade arquetípica e de simultaneidade expressiva, característico do labor de Ungaretti. Ossola mostrou, de facto, como o uso da metáfora, em Ungaretti, tende a reduzir o mais possível os vínculos lógicos e automáticos das figuras, isolando as palavras na sua nudez e na sua inocência ${ }^{5}$.

4 Poeti italiani del Novecento, a cura di P. V. Mengaldo, Milano, Mondadori, 1978 [cit. da ed. Oscar, 1990], p. 385.

5 Escreve Ossola: “[...] ridurre la prevedibilità dei legamenti, sia figurali sia sintattici, significa disporre del lessico come se non fosse mai stato usato, ricondurlo - fuori del suo sviluppo semantico - a una primitiva verginità" (cit., pp. 250-251). 
Uma forte atitude analógica caracteriza o terceto de Dante, apesar de, neste caso, a analogia ser mais clássica no estatuto da semelhança:

Come d'autunno si levan le foglie l'una appresso de l'altra, fin che 'l ramo vede a la terra tutte le sue spoglie

A tessela de referência é válida, na medida em que é capaz de manter um sentido, sem que o seu reuso num outro contexto deixe de lhe dar nova clareza e novo esplendor de significado. A metáfora de Dante conserva significados pré-existentes, mas a sua reutilização confronta-se, precisamente, com o jogo de diferenças e semelhanças no texto de chegada. A modalidade do seu uso é, ela própria, uma metáfora que alude a um processo genético de nascimento e de morte: a literatura fala da morte, da vida que se gasta como uma entidade a confrontar-se consigo própria. $\mathrm{O}$ tema da precariedade das folhas no Outono desdobra os efeitos dramáticos de um texto, a descoberta gradual de um fim, um desenlace.

Em primeiro lugar, assinale-se que Giannone ${ }^{6}$, retomando uma indicação metodológica de Ossola relativa ao "apporto di Govoni al lessico dell'Allegria"7, documenta, a propósito deste poema, uma transferência de elementos lexicais com origem em Govoni. Segundo esse crítico, a composição de Ungaretti é construída (deriverebbe) a partir do verso de um longo poema de Govoni, I mendicanti di campagna, que faz parte da recolha, L'inangurazione della primavera:

come l'autunno d'ogni albero le foglie

6 A. L. Giannone, "Ungaretti e Govoni”, in Atti del Convegno Internazionale su Giuseppe Ungaretti, t. 2, pp. 1025-1038.

7 Cit., p. 196. 
Está fora de dúvida que o verso de Govoni tem a vantagem de apresentar uma disposição dos constituintes linguísticos idêntica. Ungaretti podê-los-ia ter trabalhado a partir de ligeiras modificações sintácticas, acentuando o sentido de precariedade humana quer através da fragmentação do dodecassílabo em versos mais pequenos, quer através de uma escansão métrica com pausas. O certo é que, ao nível das estruturas não só lexicais, mas também de conteúdo, o verso de Govoni não especifica, no plano do conteúdo, um contributo apropriado ao contexto do poema de Ungaretti, a não ser quando faz da folha, no Outono, a mais patética das metáforas. O verso de Govoni poderá ter eventualmente contribuído para a fixação lexical da imagem. Mas a autorização literária para o seu emprego, encontrava-a Ungaretti, em primeira instância, no Inferno de Dante. Essa imagem, ligada à passagem das almas condenadas, levadas a embarcarem numa viagem de etterno dolore, era sem dúvida mais imediata e verdadeira. Por outro lado, o texto de Ungaretti revela a presença de uma atormentada verdade de vida e afirma-a de modo irreversível a partir de uma imagem da memória: a metáfora da precariedade do hoje é memória literária, é memória dantesca. Se, além disso, se tiver em linha de conta o percurso descrito por essa imagem, ao longo de uma tradição que vai da Bíblia a Virgílio, a ideia de uma forte instância, que não só textual, passa a ser tudo menos arbitrária ${ }^{8}$.

O uso que Ungaretti faz desse estilema de Dante, considerado na óptica daquela eventualidade para a qual Ossola

${ }^{8}$ A relação deste poema com o terceto dantesco é presentificada, antes de mais, pela recuperação de imagens que em Dante se podem dizer tópicas. A ascensão é sugerida através do carácter recursivo dessas imagens no modelo da tradição, desde a Bíblia até Virgílio. L. Paglia, L'urlo e lo stupore. Lettura di Ungaretti. L'Allegria, Firenze, Le Monnier, 2003, pp. 174-176, na sua análise da composição, faz um rápido elenco, sem os discutir, dos loci textuais da tradição, da Bíblia a Homero, de Mimnermo a Virgílio, a Dante e a Leopardi. 
chamou a atenção enquanto dever primário de qualquer leitura crítica ${ }^{9}$, é altamente significativo, e por mais de uma razão. Primeiro, em virtude do conteúdo a que faz alusão e, de seguida, porque se desenvolve a partir dos mesmos constituintes linguísticos e do mesmo efeito metafórico do original de Dante. Contudo, a citação é sempre um processo de adaptação e de separação de um contexto originário primeiro. A sua delimitação num outro segmento cultural e textual trai certamente o lugar de proveniência, mas também o traduz, o torna transmissível, permitindo uma certa adaptação cultural. É por esta via que as angústias infernais de Dante se podem transformar, em Ungaretti, em metáforas da provisoriedade e da caducidade humanas ${ }^{10}$.

A partir do momento em que o poeta ilustra com uma citação uma determinada emoção e uma determinada reflexão, situa-a num contexto histórico de referência (com indicação do lugar e da data de composição, "Bosco di Courton luglio 1918”), levando a cabo uma espécie de exegese. Uma ligação comprovativa, tendo em linha de conta a qualidade do sentido global desta operação de re-inscrição mnemónica, corre entre o inferno literário de marca dantesca e o inferno da guerra no Carso $^{11}$, pelo que - levando a situação ao ex-

9 O conceito é expresso por Ossola, cit., cujas pp. 45-46 representam, neste sentido, uma verdadeira premissa metodológica para a leitura e reconstrução do texto poético de Ungaretti.

10 A fragilidade humana, ligada ao motivo da folha, é retomada num poema homólogo, Soldato, conforme assinalado por Ossola no seu comentário a Porto sepolto. Cf. G. Ungaretti, Il Porto sepolto, a cura di C. Ossola, Milano, Il Saggiatore, 1981, p. 131.

11 A definição do Carso como inferno é antiga para Ungaretti e surge num artigo, "Zona di guerra (vivendo con il popolo)", escrito em Dezembro de 1917. Mas pense-se sobretudo na insistência com que o poeta regressou à reflexão sobre a obra dantesca, empenhando-se, em particular, na exegese do Inferno (cf. M. Verdenelli, "Alcune note su Ungaretti e Dante", in Ungaretti e i classici, a cura di M. Bruscia, R. Ceccarini, M. Petrucciani, S. Sconocchia, M. Verdenelli, Roma, Studium, 1993, pp. 159-183), ciente do carácter exemplar do 
tremo - as vicissitudes de Allegria poderão ser reconduzidas ao itinerário da primeira parte da Commedia ${ }^{12}$. Como se lê, significativamente, num passo das notas ao volume da Mondadori, Tutte le poesie, Ungaretti confere ao poeta moderno a tarefa da "esplorazione d'un personale continente d'inferno". Ele próprio, identificando o momento em que alcançou plena consciência de si como poeta, escreve, mais adiante: "Continente d'inferno, ho detto, a causa dell'assoluta solitudine che l'atto di poesia esige, a causa della singolarità del sentimento di non essere come gli altri, ma in disparte, come dannato, e come sotto il peso d'una speciale responsabilità, quella di scoprire un segreto e di rivelarlo agli altri"'13.

Como um condenado, portanto.

itinerário traçado e seguido pelo autor da Commedia, na inesgotabilidade do seu uso simbólico para a cultura ocidental, até à projecção do "inferno [che] s'apre sulla terra“", como escreve em Il dolore. Sobre as matrizes dantescas em Ungaretti, cf. Ossola, S. Campailla, "Il Carso non è più un inferno: significato di un'esperienza", in Atti del Convegno Internazionale su Giuseppe Ungaretti, t. 2, pp. 839-845, e, no mesmo volume, o contributo de A. Vallone, "Ungaretti e Dante", pp. 1385-1387.

12 Válido, obviamente, para um itinerário de leitura da poesia ungarettiana que vai do inferno psico-biológico de Allegria ao mito da Terra promessa. De um dantismo ungarettiano, não só lexical, diz-nos um crítico como Giannantonio, que na sua reconstrução da exegese dantesca de Ungaretti observava que "il moderno poeta nell'analizzare l'antico era portato a rinvenire nel poema consonanze tematiche e liriche con la propria opera" (P. Giannantonio, "Ungaretti e Dante", in Critica letteraria, 6, n. 18, 1978, pp. 3-17). Mas não passem em silêncio as conclusões sobre a pedrosidade feitas por Ossola, cit., pp. 34-35, metodologia retomada de vários modos por toda a crítica sucessiva. Cf. L. Scorrano, Modi ed esempi di dantismo novecentesco, Lecce, Adriatica Editrice Salentina, 1976, e, sobre o tema da memória virgiliana, M. Petrucciani, Il condizionale di Didone. Studi su Ungaretti, Napoli, ESI, 1985, que focam um ponto fulcral, as conexões dantescas da poesia de Ungaretti. Cf. também S. Cristaldi, "Ungaretti, Dante e il nuovo Enea", in Giuseppe Ungaretti. Identità e metamorfosi. Colloquio internazionale (Lucca, 4-6 aprile 2002), a cura di L. Fava Guzzetta, R. Gennaro, M. Luisi e F. Musarra, Lucca, Pacini Fazzi, 2005, pp. 91-134.

13 G. Ungaretti, A. Marianni, Note, in Vita d'un uomo. Tutte le poesie, a cura di L. Piccioni, Milano, Mondadori, 1969, p. 505. 
No fundo, essa persuasão põe em movimento uma reminiscência dantesca, mas é alimentada por uma realidade histórica precisa: o seu inferno pessoal, viu-o Ungaretti no Cáucaso, no absurdo de uma guerra de proporções tragicamente mundiais. A imagem do condenado é o perno linguístico que alude a um contexto infernal de referência e onde emerge o significado de uma condição humana tão débil quanto frágil. Deitai no lodo do inferno (ou da trincheira) as almas dos condenados, lá para baixo, submetidas a um eterno ritual de mortificação. Vêm à memória as pauladas dadas por Caronte, com o remo, para sacudir ("batte col remo", v. 111) da barca, como de um ramo, os condenados-folhas.

As almas condenadas - matéria volátil, terceiro elemento simbólico entre a vida e a morte -, tal como as folhas, recordam a incapacidade humana de suportar a usura do tempo: vulnerabilidade perante agentes externos que reduzem os corpos à própria matéria de lixo vegetal. As folhas caem e tornam-se espectros de si mesmas, fragmentam-se e conservam tão só a recordação do que um dia foi eflorescência vegetal. A aridez, a secura, a opacidade são atributos que definem a folha depois de cair. Pelo contrário, em vez de estarem secas e vazias, as almas dos condenados estão cheias de sentido, encerram uma obscura massa de sentimentos $\mathrm{e}$ de história.

Além disso, no texto de Ungaretti a metáfora da caducidade das folhas está ali a recordar-nos que o medo da queda é verdadeiro porque o potencial de morte ou de destruição do corpo, do objecto-homem (soldado ou condenado), é um facto verificável. Mas o medo do Outono, a anulação da esperança e portanto o esquecimento perene, a queda da árvore da vida, é um estado figurado, alegórico. A metáfora da folha, usada para a vida dos soldados, refere-se a uma condição sempre em suspenso, entre mundo literal e mundo figurado. Os soldados são as folhas que caem com o vento 
da guerra. Reflectem, analogicamente, a aridez figurada da condição das almas infernais, sacudidas pela fúria de Caronte. A queda é resultado do encontro entre a violência do ambiente circundante e a condição de perene espera da morte. Ungaretti parece ter consciência dessas implicações do tema da queda / caducidade: consequências já inscritas no verbo Si sta, fundado sobre a tenção entre o momento da declaração (o hoje) e aquilo que irá acontecer (o amanhã), entre o que sempre foi (o ontem) e o sempre-igual da condição presente (a guerra). É previsto o que será (os soldados serão e eram folhas da árvore da vida), a passagem de gerações de homens pela face da terra, a inversão do sublime: todos estes significados caíram, desde o início, na imagem das folhas precárias. A relação entre vida e morte mantém-se, através de uma relação estável que vai de Dante a Ungaretti. A folha enuncia a potencial unidade entre um antes e um depois, entre aquilo que era vida e aquilo que será morte.

Em Dante, as folhas si levano, neste caso estão, mas a propriedade comum aos dois textos é sempre a da queda e da caducidade ${ }^{14}$. A imagem dantesca do ramo (v. 113) possui um valor e um poder representativo que ganha continuidade nas árvores de Ungaretti (e eventualmente no $B o s c 0^{15}$ ): as folhas representam um grumo de matéria que remete para um significado indiscutível. Destruição, friabilidade, afastamento: a folha está ligada à queda, à morte. A folha alude a

14 Ossola, num subtil jogo de reenvios, aproxima o significado deste verbo, usado na forma impessoal, do final de Nostalgia ("e come portati via / si rimane"), relacionando-o com um mesmo sentido de fragilidade humana. Cf. Ungaretti, Il Porto sepolto, p. 213.

15 Alusão a um verdadeiro bosque, o Bosque de Courton, na frente francesa, para onde Ungaretti foi enviado no último ano da Guerra e onde estavam acampados os regimentos. Este pormenor "permette allora di considerare gli alberi e le foglie non solo come costituenti immaginari dell'analogia ma anche come elementi percepiti e reali" (A. Bertoni, J. Sisco, Montale vs. Ungaretti, Roma, Carocci, 2003, p. 49). 
qualquer coisa de precedente, dotada de sentido e de corpo, que já não existe, matéria indistinta que é sinal, o sinal de uma recordação de qualquer coisa (ou de alguém) acerca da qual nada se sabe. Sintacticamente, o poema apoia-se na presença de um único verbo, expresso de forma impessoal (Si sta), precisamente o estar que Ungaretti carrega de significado, isolando-o em posição dominante ${ }^{16}$. O resultado é, no plano semântico, oposição e inversão de uma estabilidade ligada à acção e à condição de estar, passagem ao sentido de precariedade próprio de quem vive numa situação contingente (os soldados na guerra), próprio da existência em geral (a geração cíclica das folhas).

A metáfora vegetal é escolhida não só por corresponder a uma imagem tradicional de secura e aridez (e aqui entra em cena o tertium comparationis, que é o Outono), mas também por corresponder analogicamente a uma experiência de morte. A ligação analógica entre Outono e morte é a volatilização das folhas, a dispersão e a queda: o que também encontramos em Dante, só que nesse caso é-nos mostrado o lugar da dissipação, da queda em sentido moral, que é o inferno. Pelo contrário, o texto de Ungaretti não nomeia a causa da morte (a guerra), afirmando-a antes na sua extratextualidade. Se há alguma coisa da actual condição que o poeta teme, é mesmo a extrema caducidade, o perigo extremo da vida de um soldado. A vida de soldado é, de facto, tudo aquilo que, no contexto bélico, corresponde ao oposto da permanência e da continuidade. Vimos como a metáfora da folha consente a oposição polar ou binária entre árvore / vida e Outono / morte.

${ }^{16}$ Um uso semelhante também se encontra em Natale ("Sto / con le quattro / capriole") e em Trasfigurazione ("Sto / addossato a un tumulo"). Sobre a pregnância do verbo em posição privilegiada, cf. G. Cambon, La poesia di Ungaretti, Torino, Einaudi, 1976, p. 54. Para um aprofundamento do nível sintáctico da composição, cf. P. Briganti, W. Spaggiari, in Poesia \& C., Bologna, Zanichelli, 1991, p. 177. 
Ungaretti retoma de Dante, sempre através de linhas internas e tesselas da memória, a força centralizadora e a revelação da palavra. Mas desenvolve-as sem ênfase. Pense-se na condição implícita do eu poetante-soldado, pois o poeta é um soldado no momento em que escreve, é (subentendido) personagem ainda viva (e verdadeira), tal como Dante é personagem viva (mas de ficção) que percorre as estradas infernais. Mas esta sobreposição metonímica tem por tema qualquer coisa de metafórico, que é a própria poesia: a contar-nos o que está submetido à destruição e à morte. A poesia que nos fala da morte é uma metáfora. Uma metáfora de segundo grau. O resultado é uma representação da ânsia de desaparecer, mas, ao mesmo tempo, um desejo de testemunhar, de ficar, de estar.

A vida, como a poesia - neste ponto, a diferença entre as duas é ilusória - está condenada a concluir-se. A vida parece estar inteiramente centrada na metáfora perdida, aquilo que procurou ser. A metáfora é, todavia, vaga - Outono, árvores, folhas, uma sequência redutível a um denominador único, a morte. O facto de a folha ser evocada para sancionar uma conclusão e dizer que o significado da vida se conclui no acto de cair permite defini-la como metáfora do texto que no acto de leitura conclui o seu significado: "il libro poteva ridiventare, per lui, i frammenti di foglietti dispersi, anche se, ad attimi, rilucenti come le foglie al vento su cui restavano le tracce della sentenza di Sibilla" ${ }^{17}$. Mais uma remissão dantesca.

Zanzotto percorre de novo, fulmíneo, um motivo já identificado por Ossola, com referência às folhas da Sibila em Dante. É um tipo de metáfora que evoca o medo da morte e a síntese da existência, a unidade da consciência, do estar-aí e do seu oposto. A folha atrai a atenção, a sua importância

17 A. Zanzotto, Testimonianza, in Scritti sulla letteratura. Fantasie di avvicinamento, Milano, Mondadori, 2001, vol. 1, a cura di G. M. Villalta, p. 98. 
semântica é dramática. Mas se se confia o significado da vida (e do texto) a uma metáfora, isso é para o tornar legível, à semelhança das folhas dispersas da Sibila dantesca.

O alerta para essa caducidade que Ungaretti ousa afirmar e pedir para si é um alerta absoluto relativamente ao carácter aleatório da guerra, sendo clara a sua recusa de conferir à experiência, qualquer que ela seja (também a literária) o poder de pôr fim a essa alienação. Certamente que nem a vida, nem tão pouco a literatura, podem superar a essencial aridez do eu e do mundo.

Tradução de Rita Marnoto 